\title{
ACESSIBILIDADE INFORMACIONAL DE PCD NO CONTEXTO DA LEI DE ACESSO À INFORMAÇÃO: desafios para estudo de usuários
}

\author{
INFORMATION ACCESSIBILITY OF USERS IN THE CONTEXT OF THE \\ ACCESS TO INFORMATION LAW: challenges for user studies
}

\author{
Asa Fujino \\ USP
}

\section{RESUMO}

A Lei no 12.527/2011, conhecida como Lei de Acesso à Informação (LAI), regula o direito de acesso à informação pública, visando a promoção da cidadania e o controle social da gestão pública. A Controladoria-Geral da União (CGU), atual Ministério da Transparência, Fiscalização e Controle (MTFC), autoridade responsável pelo monitoramento do cumprimento da lei em todo poder executivo, estabeleceu procedimentos para processar pedidos de informação e obrigações relativas à divulgação pró-ativa e ao dever de fornecer dados em formato aberto e não proprietário e as sanções para aqueles que negam o acesso a informações não protegidas por lei. No entanto, na Ciência da Informação, a acessibilidade informacional depende do conhecimento das necessidades de informação do potencial usuário, além dos aspectos que envolvem a infraestrutura para acesso e divulgação, condições fundamentais para o desenvolvimento de mediações que viabilizem o acesso cognitivo e apropriação das informações pelo usuário. Trata-se de uma reflexão sobre os desafios teórico-metodológicos para realização de estudos de necessidades de informação e estudos sobre comportamento na busca de informação do potencial usuário, com o objetivo de subsidiar políticas públicas de informação.

Palavras-chave: Lei de acesso à informação. Estudos de Usuário. Acessibilidade Informacional de Usuários.

\section{ABSTRACT}

Law 1.527 / 2011, known as the Law on Access to Information (LAI), regulates the right of access to public information, aimed at promoting citizenship and social control of public management. The Office of the Comptroller General of the Union (CGU), the current Ministry of Transparency, Oversight and Control (MTFC), the authority responsible for monitoring compliance with the law in every executive branch, has established procedures for processing requests for information and obligations regarding proactive disclosure and the duty to provide data in an open and nonproprietary format and penalties for those who deny access to information not protected by law. However, in Information Science, information accessibility depends on the knowledge of the information needs of the potential user, as well as the aspects that involve the infrastructure for access and disclosure, fundamental conditions for the development of mediations that enable cognitive access and appropriation of information by the user. It is a reflection on the theoreticalmethodological challenges to carry out studies on user's information needs and user's information seeking behaviour in order to subsidize public information policies.

Keywords: Access to Information Law. User Studies. Information Accessibility of Users. 


\section{INTRODUÇÃO}

A Lei no 12.527, de 18 de novembro de 2011, conhecida como Lei de Acesso à informação (LAI), regulamentada pelos Decretos Federais no 7.724 de 2012 e no 8.408 de 2015, tem como objetivo garantir ao cidadão o acesso à informação pública visando a promoção da cidadania e o controle social da gestão pública. Neste sentido, torna obrigatória a disponibilização de informações de interesse público, produzidas ou sob a responsabilidade de entidades públicas, em meio eletrônico de forma objetiva, transparente, clara e em linguagem de fácil compreensão (BRASIL, 2011).

Na promulgação da Lei foi previsto que a Controladoria-Geral da União (CGU), atual Ministério da Transparência, Fiscalização e Controle (MTFC) seria a autoridade responsável pelo monitoramento do cumprimento da LAI em todo poder executivo federal e cada órgão ou entidade deve indicar um dirigente para desempenhar esta atribuição.

Em 2013, a Controladoria-Geral da União determinou que o amplo acesso à informação é a regra e o sigilo é exceção; estabeleceu que todas as entidades deveriam criar procedimentos que facilitem o acesso; e definiu princípios orientadores da LAI: publicidade máxima; transparência ativa; abertura de dados; promoção de um governo aberto; além da criação de procedimentos que facilitem o acesso (CONTROLADORIAGERAL DA UNIÃO, 2011).

No entanto, partimos do pressuposto que a Informação, vista como instrumento para Inclusão Social, só tem sentido se puder contribuir para empoderar cidadãos na construção de uma sociedade em que comunicação, educação e cultura tenham como base o respeito à diferença e a igualdade de oportunidades para todos.

Neste sentido, entendemos que a disponibilização da informação, conforme prevista na lei e, de acordo com os princípios estabelecidos pela CGU, não garante o acesso à informação por parte do potencial usuário, uma vez que a acessibilidade, na perspectiva da Ciência da Informação, não se restringe apenas à materialidade do acesso, mas envolve aspectos cognitivos do usuário e a compreensão das práticas sociais de informação são elementos necessários para possibilitar o desenvolvimento de mediações que possibilitem o acesso e apropriação.

Assim, para o cumprimento efetivo da lei, torna-se necessário compreender as formas de produção, circulação e acesso à informação na atualidade e, embora não 
previsto na lei, o estudo de potenciais usuários da informação pública nos diferentes regimes de informação assume caráter de obrigatoriedade para as instituições públicas. Propostas teórico-metodológicas para realização desses estudos tornam-se desafio acadêmico considerável para pesquisadores da Ciência da Informação, levando-se em conta as variáveis a serem analisadas nos diferentes contextos de uso da informação e as características particulares dos interessados, ai incluídas as Pessoas com Deficiência PcD, que, como qualquer cidadão, têm direito ao acesso à informação e é responsabilidade dos provedores de informação considerar interfaces amigáveis para garantir o acesso de todos.

Pretende-se, neste espaço, refletir sobre três aspectos envolvidos nesta discussão: a) o papel da informação na sociedade contemporânea e as novas práticas sociais que a sustentam; b) o regime de informação vigente no Brasil e o lugar do cidadão nas políticas públicas brasileiras voltadas para a inclusão social: a Convenção sobre os Direitos das Pessoas com Deficiência - CDPD (ONU, 2006), a LBI - Lei Brasileira de Inclusão de Pessoas com Deficiência - Lei 13.146/2015 e a Lei de Acesso à Informação - Lei 12.527/2011 e os seus reflexos no atendimento a esses usuários nas bibliotecas e dispositivos culturais; e c) a Ciência da Informação e suas contribuições para a inserção social da Informação e Inclusão Social, os dispositivos de informação e os desafios para a interação significativa com o cidadão.

\section{SOCIEDADE CONTEMPORÂNEA E A INFORMAÇÃO}

A sociedade contemporânea é profundamente marcada pela separação do tempo e espaço, mas para além dos aspectos geográficos há que se pensar no "lugar da cultura", enquanto espaço de significação, nos quais as práticas sociais adquirem diferentes significados. As Tecnologias de Informação e Comunicação deixam de ser elemento de mediação entre o homem e a realidade e passam a expressar uma nova razão cognitiva.

Giddens (1991, p.17-20) discorre sobre a padronização do tempo e reflete sobre o modo de vida na pós-modernidade e os impactos do deslocamento do espaço do lugar, que ele denomina como processo de desencaixe, nas práticas sociais. 0 autor entende que o lugar, enquanto localização geográfica onde se desenvolvem atividades sociais, era na pré-modernidade conectado localmente com o tempo. Entretanto, as alterações na 
organização social do tempo levaram a deslocamentos das relações sociais de interação que ocorriam nos contextos locais e deram origem a novos modelos de interações sociais em locais moldados por influências sociais externas ao local e marcadas por extensões indefinidas de tempo-espaço, de onde surge um "mundo fugitivo de deslocamentos e incertezas" no qual o progresso do conhecimento é envolvido pela imprevisibilidade e incerteza e sua construção passa pela reflexão sobre as práticas sociais.

Assim, segundo o autor, a reflexibilidade seria uma característica inerente e necessária à ação humana e está na base da reprodução do sistema, pois o ser humano está em permanente "contato com as bases do que fazem como parte integrante do fazer". Mas, ao romper com a tradição de práticas sociais recorrentes, as novas práticas sociais deverão ser reformuladas. 0 autor identifica, nas instituições, a existência de dois mecanismos de desencaixe que atuariam como extensão de sistemas sociais : as "fichas simbólicas", que seriam meios de intercâmbio que podem ser circulados socialmente, independente das características específicas dos indivíduos ou grupos que lidam com eles, como o dinheiro, e "sistemas peritos de excelência técnica ou competência profissional" que oferecem garantias de expectativas com base nos instrumentos que avaliam e fundamentam a produção do conhecimento técnico , e pela crítica pública usada para controlar sua forma. No entanto, ressalta que ambos dependem da confiança de que tais sistemas funcionem de acordo com as expectativas dos usuários, de modo que a credibilidade em tais mecanismos envolve também riscos, que seriam resultantes das circunstâncias e das limitações de conhecimento sobre tais sistemas por parte dos seus usuários. Assim, para o autor, as práticas sociais devem ser "constantemente examinadas e reformadas à luz de informação renovada sobre estas próprias práticas, alterando constitutivamente seu caráter" (GIDDENS, 1991, p.35-37).

Pensando a informação neste contexto, trazemos o desafio proposto por Frohman (2008), em palestra sobre o caráter público, material e social da informação, no VII ENANCIB - Encontro Nacional de Pesquisa e Pós-Graduação em Ciência da Informação, ocorrido em Marília em 2006: “Como conciliar estudos sobre o fenômeno da informação em nosso tempo, com estudos das práticas sociais e públicas, das realidades políticas, da economia e da cultura?"

Para refletir sobre este desafio, partimos do texto de Paim e Nehmy (1998) que, ao aplicar as categorias propostas por Giddens (1991) ao contexto da Ciência da 
informação e assumindo o conceito de reflexibilidade, consideram a informação como parte da prática cotidiana e observam que cada nova informação ao se agregar ao conjunto de conhecimentos do usuário, resultará em "reoordenamento, reestruturação ou revisão da compreensão inicial", não sendo possível "medir o conhecimento transformado e adicionado, nem em quantidade nem em qualidade", devendo a recorrência à informação assumir a “característica de hábito, rotina na vida dos indivíduos" (PAIM; NEHMY, 1998. p. 85).

Por outro lado, para as autoras, os sistemas de informação técnico-científico poderiam ser vistos como sistemas peritos, a partir de pressupostos de legitimidade e excelência implícitos em sua constituição. Esta perspectiva possibilitaria pensar a avaliação da informação e dos sistemas a partir de propostas relativas ao conteúdo e significado que assumem na aproximação aos interesses de quem usa a informação, de modo que a legitimação dos sistemas pelos usuários, seria fruto da qualidade determinada no momento da sua interação com o sistema e, portanto, a posteriori (PAIM; NEHMY, 1998. p. 87).

Neste sentido, retomamos o conceito de materialidade de Frohman (2008, p. 20 21) "como uma ponte que liga duas áreas conceituais: informação, por um lado, e práticas públicas e sociais por outro".

Partindo da ideia da materialidade dos enunciados do ponto de vista do filósofo Michel Foucault, o autor propõe investigação sobre a "materialidade da informação", propriedade que confere estabilidade aos enunciados, condição para que estes circulem socialmente e criem efeitos de sentido, para entender como os enunciados são estabilizados, se "massificam e ganham poder" ao longo do tempo. A proposta é alternativa ao conceito "mentalista abstrato, no qual a informação é concebida como algo que está presente na mente em estado de compreensão" (FROHMAN, 2008. p.22), visão, segundo ele, que privilegia os estudos da informação focados nos indivíduos, mas restringe os estudos dos efeitos dos regimes de informação, os aspectos sociais, públicos, econômicos e culturais da informação nas mudanças na consciência individual.

Assim, propõe pensar documentos como mensagens que entram nos circuitos institucionais para serem analisados, reinscritos e transcritos. Tais documentos contém enunciados estabilizados, institucionalizados em diferentes tipos de dispositivos, que circulam através e dentre as instituições resultando na materialização da informação. 
Complementarmente, o autor alerta para a velocidade da circulação de documentos digitais, cuja produção não necessariamente embute intencionalidade na geração dos enunciados, e no peso que adquirem na atualidade, impactada pelos aparatos tecnológicos que facilitam e multiplicam formas de coleta, processamento e utilização da informação. Exemplifica com registros criminais de pequenos delitos que foram legalmente expurgados dos registros impressos das instituições, mas permaneceram acessíveis nas redes, causando a perenidade do registro na ficha individual dos indivíduos que, embora legalmente absolvidos da sentença do passado, jamais terão controle sobre o enunciado materializado via um documento digital que continuará circulando em diferentes dispositivos de informação (FROHMAN, 2008, p.28).

\section{REGIME DE INFORMAÇÃO VIGENTE E CIDADANIA}

Neste tópico, torna-se imprescindível tratar do lugar do cidadão na atual sociedade, a partir da legislação: A Convenção sobre os Direitos das Pessoas com Deficiência - CDPD (ONU, 2006), a LBI - Lei Brasileira de Inclusão de Pessoas com Deficiência - Lei 13.146/2015 e a LAI - Lei de Acesso à Informação, e apresentar algumas experiências brasileiras de implementação de políticas de acessibilidade informacional em dispositivos de informação.

Para introduzir o conceito de informação pública, recorremos a um documento da Organização das Nações Unidas para Educação, a Ciência e a Cultura (UNESCO) publicado com o objetivo de estabelecer diretrizes políticas para o desenvolvimento e a promoção da informação governamental de domínio público:

A informação de domínio público refere-se à informação publicamente acessível, cuja utilização não infringe qualquer direito legal, ou qualquer obrigação de confidencialidade. Refere-se, portanto, por um lado, ao domínio de todos os trabalhos ou objetos associados a tais direitos, os quais podem ser explorados por todos sem qualquer autorização, por exemplo quando a proteção não é concedida por lei nacional ou internacional, ou devido à expiração do termo de proteção. Refere-se, por outro lado, a dados públicos e informações oficiais produzidas e voluntariamente disponibilizadas por governos ou organizações internacionais. (UHLIR, 2006, p. 24)

A decisão sobre os tipos de informação do setor público que são franqueadas ao domínio público depende muito da abordagem de cada país com relação às políticas de informação e de governança, assim como de sua capacidade e 
práticas de disseminação da informação (em particular com relação à internet). (UHLIR, 2006, p. 28)

Quanto à Lei de acesso à informação, trata-se da Lei no 12.527 , de 18 de novembro de 2011 - LAI, regulamentada pelos Decretos Federais no 7.724 de 2012 e no 8.408 de 2016. Tem como base o princípio de que todos os cidadãos têm o acesso à informação como um direito fundamental, como previsto no Título I - Dos Direitos e Garantias Fundamentais, Capítulo I - Dos Direitos e Deveres Individuais e Coletivos, inciso XXXIII do art. 5을

XXXIII - todos têm direito a receber dos órgãos públicos informações de seu interesse particular, ou de interesse coletivo ou geral, que serão prestadas no prazo da lei, sob pena de responsabilidade, ressalvadas aquelas cujo sigilo seja imprescindível à segurança da sociedade e do Estado. (BRASIL, 1988)

A lei tem como objetivo regulamentar o direito constitucional de acesso dos brasileiros às informações públicas

Os responsáveis no executivo federal foram assim determinados: Controladoria Geral da União (CGU), que foi extinta e torna-se oficialmente o Ministério da Transparência, Fiscalização e Controle (MTFC) e é responsável pelo monitoramento da Lei em todo Poder Executivo Federal; e cada órgão e/ou entidade deve indicar um dirigente para desempenhar a atribuição como autoridade de monitoramento, responsável por verificar o cumprimento da LAI no ente público a que pertence. (BRASIL, 2011).

A LAI tem como princípios norteadores: o da publicidade máxima; da transparência ativa; da abertura de dados; da promoção de um governo aberto; da criação de procedimentos que facilitem o acesso, e determina que o amplo acesso à informação é a regra e o sigilo, a exceção (CONTROLADORIA-GERAL DA UNIÃO, 2011).

Os conceitos entendidos para o efeito da Lei são:

I - informação: dados, processados ou não, que podem ser utilizados para produção e transmissão de conhecimento, contidos em qualquer meio, suporte ou formato;

II - documento: unidade de registro de informações, qualquer que seja o suporte ou formato;

III - informação sigilosa: aquela submetida temporariamente à restrição de acesso público em razão de sua imprescindibilidade para a segurança da sociedade e do Estado; 
IV - informação pessoal: aquela relacionada à pessoa natural identificada ou identificável;

V - tratamento da informação: conjunto de ações referentes à produção, recepção, classificação, utilização, acesso, reprodução, transporte, transmissão, distribuição, arquivamento, armazenamento, eliminação, avaliação, destinação ou controle da informação;

VI - disponibilidade: qualidade da informação que pode ser conhecida e utilizada por indivíduos, equipamentos ou sistemas autorizados;

VII - autenticidade: qualidade da informação que tenha sido produzida, expedida, recebida ou modificada por determinado indivíduo, equipamento ou sistema;

VIII - integridade: qualidade da informação não modificada, inclusive quanto à origem, trânsito e destino;

IX - primariedade: qualidade da informação coletada na fonte, com o máximo de detalhamento possível, sem modificações. (BRASIL, 2011)

\section{0 cidadão, conforme o Art. 7o, tem o direito de obter pela Lei:}

I - orientação sobre os procedimentos para a consecução de acesso, bem como sobre o local onde poderá ser encontrada ou obtida a informação almejada;

II - informação contida em registros ou documentos, produzidos ou acumulados por seus órgãos ou entidades, recolhidos ou não a arquivos públicos;

III - informação produzida ou custodiada por pessoa física ou entidade privada decorrente de qualquer vínculo com seus órgãos ou entidades, mesmo que esse vínculo já tenha cessado;

IV - informação primária, íntegra, autêntica e atualizada;

$\mathrm{V}$ - informação sobre atividades exercidas pelos órgãos e entidades, inclusive as relativas à sua política, organização e serviços;

VI - informação pertinente à administração do patrimônio público, utilização de recursos públicos, licitação, contratos administrativos; e

VII - informação relativa:

a) à implementação, acompanhamento e resultados dos programas, projetos e ações dos órgãos e entidades públicas, bem como metas e indicadores propostos;

b) ao resultado de inspeções, auditorias, prestações e tomadas de contas realizadas pelos órgãos de controle interno e externo, incluindo prestações de contas relativas a exercícios anteriores. (BRASIL, 2011)

Os órgãos e entidades da administração pública deverão publicar em seus sites eletrônicos informações sobre:

a) estrutura organizacional e competências dos órgãos, além dos endereços e telefones de suas unidades e horários de atendimento ao público;

b) programas, projetos, ações, obras e atividades, indicando a unidade responsável, principais metas e resultados e indicadores (se existirem);

c) repasses ou transferências de recursos financeiros;

d) execução orçamentária e financeira detalhada;

e) procedimentos licitatórios, com os contratos celebrados e notas de empenho emitidas;

f) remuneração recebida por servidores e empregados públicos de maneira individualizada;

g) respostas a perguntas mais frequentes da sociedade;

h) contato da autoridade de monitoramento da LAI na instituição e informações sobre o Serviço de Informações ao Cidadão; 
i) informações classificadas e desclassificadas, nos termos do art. 45, I e II do Decreto 7.724/2012. (ACESSO A INFORMAÇÃO, 2016)

0 art. $9^{\circ}$ da LAI (BRASIL, 2011) instituiu como dever do Estado a criação de um local físico e virtual de contato entre a sociedade e o setor público, que é o Serviço de Informações ao Cidadão - SIC. O local deve ser de fácil acesso e identificação pela sociedade garantindo o atendimento presencial ao cidadão. (CONTROLADORIA-GERAL DA UNIÃO, 2011).

O Sistema Eletrônico do Serviço de Informação ao Cidadão (e-SIC) foi criado para centralizar as entradas e saídas de todos os pedidos de acesso dirigidos ao Poder Executivo Federal pela Internet e é facilitada, pois "os dados já são organizados de forma inteligente e fornecem informações úteis também para o gestor público" (CONTROLADORIA-GERAL DA UNIÃO, 2011)

A lei também estabelece que os sites na internet dos órgãos e entidades públicas utilizados para exercer a Transparência Ativa deverão seguir o seguinte rol de requisitos estabelecidos no inciso $3 \stackrel{\circ}{\text { do artigo }} 8^{\circ}$ da LAI:

\footnotetext{
I - conter ferramenta de pesquisa de conteúdo que permita o acesso à informação de forma objetiva, transparente, clara e em linguagem de fácil compreensão;

II - possibilitar a gravação de relatórios em diversos formatos eletrônicos, inclusive abertos e não proprietários, tais como planilhas e texto, de modo a facilitar a análise das informações;

III - possibilitar o acesso automatizado por sistemas externos em formatos abertos, estruturados e legíveis por máquina;

IV - divulgar em detalhes os formatos utilizados para estruturação da informação;

$\mathrm{V}$ - garantir a autenticidade e a integridade das informações disponíveis para acesso;

VI - manter atualizadas as informações disponíveis para acesso;

VII - indicar local e instruções que permitam ao interessado comunicar-se, por via eletrônica ou telefônica, com o órgão ou entidade detentora do sítio;

VIII - adotar as medidas necessárias para garantir a acessibilidade de conteúdo para pessoas com deficiência, nos termos do art. 17 da Lei no 10.098, de 19 de dezembro de 2000, e do art. 9o da Convenção sobre os Direitos das Pessoas com Deficiência, aprovada pelo Decreto Legislativo no 186, de 9 de julho de 2008. (BRASIL, 2011).
}

0 direito relativo à garantia de acessibilidade na LAI envolve o direito dos interessados que queiram obter informação à facilidade para encontrá-las, e o direito das pessoas com deficiência de acessarem a informação e prevê que é dever do gestor 
público garantir que a informação seja acessível (CONTROLADORIA-GERAL DA UNIÃO, 2011).

Conforme Marta Gil, coordenadora executiva da Amankay instituto de estudos e pesquisa que atua na área da Deficiência, nos anos 70 a deficiência era um problema que estava na pessoa e, portanto, a pessoa é que deveria ser modificada para se tornar apta a viver em sociedade. A partir dos anos 90, surgiu o princípio da Inclusão, no qual a deficiência é vista como resultado da incapacidade da sociedade em atender às necessidades dessa mesma pessoa e, nesse sentido, a sociedade deve se tornar capaz de acolher todos, sem restrição (AMANKAY, s.d.)

Para Resende e Vital (2008, p. 103), a sociedade inclusiva deve ressaltar o respeito à diferença e a aplicação dos direitos humanos, a igualdade de oportunidades e o fortalecimento da comunicação, a educação e a cultura como princípios de participação ativa na sociedade. Para o autor, quando as pessoas se apropriam desta realidade a cooperação mútua e interação social passam a ser efetivas. De fato, a consciência sobre o respeito à diferença e aos direitos humanos começa a se fazer presente nas universidades brasileiras, como exemplifica o portal sobre acessibilidade da UFC - Universidade Federal do Ceará, no qual a acessibilidade é considerada "condição fundamental e imprescindível a todo e qualquer processo de inclusão social" tanto na perspectiva dos direitos da $\mathrm{PcD}$, quanto nas atitudes que se espera dos cidadãos às pessoas com deficiência.

A Convenção sobre os Direitos das Pessoas com Deficiência - CDPD (ONU, 2006), estabelece que a Acessibilidade é DIREITO de todas as pessoas. No Brasil, esse direito foi ratificado com equivalência de Emenda Constitucional (Decreto Legislativo 186/2008 e promulgada pelo Decreto Executivo 6949/2009). A CDPD menciona a acessibilidade em diversos pontos, desde o Preâmbulo. 0 artigo 21 foca especificamente a liberdade de expressão e opinião e acesso à informação.

A LBI - Lei Brasileira de Inclusão de Pessoas com Deficiência - Lei 13.146/2015 entrou em vigor em 2016. Ela concretiza e operacionaliza os conceitos, valores e diretrizes da CDPD e o capítulo 1 do Título III da LBI é voltado para todos os aspectos sobre acessibilidade.

A Lei de Acessibilidade - Decreto 5.296/2004, por sua vez, regulamenta as Lei no. 10.048, de 8 de novembro de 2000, que dá prioridade de atendimento às pessoas que especifica, e no. 10.098, de 19 de dezembro de 2000, que estabelece normas gerais e 
critérios básicos para a promoção da acessibilidade das pessoas portadoras de deficiência ou com mobilidade reduzida. Embora considerada avançada em muitos pontos, enfrenta diversas barreiras para sua implementação em função das questões orçamentárias das instituições para garantir que a sociedade, de forma geral, se adapte às necessidades de todos os cidadãos, embora normas, como a NBR 9050, já tenham sido desenvolvidas para assegurar acessibilidade a edificações, mobiliário, espaços e equipamentos urbanos em cumprimento às leis.

Sassaki (2011, p.1), ao tratar dos contextos de acessibilidade enumera:

- Acessibilidade arquitetônica: sem barreiras ambientais físicas, nas residências, nos edifícios, nos espaços urbanos, nos equipamentos urbanos, nos meios de transporte individual ou coletivo;

- Acessibilidade comunicacional: sem barreiras na comunicação interpessoal (face-a-face, língua de sinais), escrita (jornal, revista, livro, carta, apostila etc., incluindo textos em braile, uso do computador portátil), virtual (acessibilidade digital);

- Acessibilidade metodológica: sem barreiras nos métodos e técnicas de estudo (escolar), de trabalho (profissional), de ação comunitária (social, cultural, artística etc.), de educação dos filhos (familiar);

- Acessibilidade instrumental: sem barreiras nos instrumentos, utensílios e ferramentas de estudo (escolar), de trabalho (profissional), de lazer e recreação (comunitária, turística, esportiva etc.);

- Acessibilidade programática: sem barreiras invisíveis embutidas em políticas públicas (leis, decretos, portarias etc.), normas e regulamentos (institucionais, empresariais etc.);

- Acessibilidade atitudinal: sem preconceitos, estigmas, estereótipos e discriminações, nas pessoas em geral.

No âmbito educacional, o Ministério da Educação-MEC assinou a Portaria $\mathrm{n}^{\mathrm{o}}$ 1.679, de 2 de Dezembro de 1999, que "Dispõe sobre os requisitos de acessibilidade de pessoas portadoras de deficiência, para instruir os processos de autorização e de reconhecimento de cursos, e de credenciamento de instituições". Aspectos de reprodução de obras literárias, artísticas ou científicas em suportes para deficientes visuais, encontram respaldo na Lei №9610, de 19 de Fevereiro de 1998, no Art. 46. que prevê

Não constitui ofensa aos direitos autorais [...]a reprodução [...] de obras literárias, artísticas ou científicas, para uso exclusivo de deficientes visuais, sempre que a reprodução, sem fins comerciais, seja feita mediante o sistema Braille ou outro procedimento em qualquer suporte para esses destinatários. 
No que se refere aos direitos de acesso à informação em dispositivos de informação, sob responsabilidade de bibliotecários e profissionais da informação, merece destaque decisão do Conselho Diretivo da International Federation of Library Associations and Institutions (IFLA) que, em agosto de 2012, aprovou o "Código de Ética da IFLA para bibliotecários e outros profissionais da informação". 0 código apresenta uma série de recomendações para a orientação de bibliotecários e profissionais da informação, bem como para apreciação de associações de bibliotecas e instituições afins, no qual reconhece a responsabilidade social dos profissionais em assegurar o acesso à informação para todos os cidadãos e reitera a convicção da vinculação entre compartilhamento de informação e reconhecimento dos direitos de informação como expressos na Declaração Universal dos Direitos Humanos das Nações Unidas. O código, em seu capítulo 2. "Responsabilidades para com os indivíduos e para a sociedade" estabelece

\begin{abstract}
Para promover a inclusão e erradicar a discriminação, os bibliotecários e outros profissionais da informação asseguram que o direito de acesso à informação não pode ser negado e que serviços equitativos são fornecidos para qualquer pessoa de qualquer idade, nacionalidade, crença política, condição física ou mental, gênero, descendência, educação, renda, condição imigratória ou de asilo, situação matrimonial, origem, raça, religião e orientação sexual. Os bibliotecários e outros profissionais da informação respeitam línguas minoritárias de um país e seu direito de acesso à informação em seu próprio idioma. (IFLA, 2012. p. 3)
\end{abstract}

Entretanto, apesar de avanços significativos nas legislações governamentais em âmbitos nacionais e internacionais e no âmbito das categorias educacionais e profissionais, que visam garantir o acesso à informação pelo cidadão, aí incluídos $\mathrm{PcD}$, há, segundo Deise Tallarico Pupo

uma considerável discrepância entre a ideologia da pressa, inerente ao avanço tecnológico, e os tímidos avanços sociais. Essa é uma imperdoável lacuna que necessita ser preenchida por pessoas que acreditam na inclusão como ruptura dos paradigmas existentes, para não deixar ninguém de fora na construção de ambientes acessíveis (PUPO, 2008, p.11)

Assim, listamos algumas experiências nos âmbitos executivo e acadêmico que visam promover a acessibilidade em bibliotecas.

Merece registro o "Projeto Acessibilidade em Bibliotecas Públicas", iniciativa do Sistema Nacional de Bibliotecas Públicas (SNBP), da Diretoria de Livro, Leitura, 
Literatura e Bibliotecas (DLLLB), do Ministério da Cultura (MinC), com colaboração do "Mais Diferenças", organização da sociedade civil de interesse público, responsável pela execução e parceria com o Plano Nacional do Livro e Leitura (PNLL), que tem como objetivos e metas

ampliar e qualificar a acessibilidade em dez bibliotecas públicas selecionadas pelo SNBP. Desta forma, busca-se contribuir com a democratização do acesso às bibliotecas públicas e com a garantia dos direitos das pessoas com deficiência ao conhecimento e informação por meio de ações que favoreçam a equiparação de oportunidades; contribuir para o debate e a formulação de políticas públicas de inclusão nestes equipamentos culturais, em conformidade com o marco político e legal dos direitos das pessoas com deficiência no país e em consonância com os acordos internacionais da área; auxiliar o fortalecimento das políticas, programas e projetos no campo do livro e leitura numa perspectiva acessível e inclusiva. (SNBP, s. d.).

0 projeto inicial incluiu 10 (dez) bibliotecas públicas de diferentes estados do país e o desenvolvimento foi programado em etapas: Diagnóstico; Comunicação e produção de conteúdo acessível; Qualificação do acervo; Acesso à Tecnologia Assistiva; Capacitação; Fomento ao trabalho em rede; Mobilização e sistematização. Foram previstos recursos e serviços que contribuem para proporcionar ou ampliar habilidades funcionais de pessoas com deficiência, considerando 5(cinco) classes de deficiência: intelectual, física, visual, auditiva e múltipla, de acordo com o previsto na lei 10683/2003 e consequentemente promover autonomia e inclusão.

Outro projeto de destaque é o da Universidade Estadual de Campinas-UNICAMP, denominado "Projeto Laboratório de Acessibilidade - LAB", iniciado em 1998 e inaugurado em 2003 na Biblioteca Central Cesar Lattes- BCCL da Unicamp. 0 projeto tve como objetivo ser referência no campo da inclusão social e digital em unidades de informação, proporcionando acesso ao conhecimento a todos em espaços inclusivos .(UNICAMP, s.d) 0 livro "Acessibilidade: discurso e prática no cotidiano das bibliotecas" (PUPO; MELO; FERRÉS, 2008) traz a experiência de construção de uma biblioteca inclusiva, do planejamento de seus aspectos arquitetônicos, incluindo disponibilização de móveis e organização dos espaços internos, como o balcão de atendimento, até o cuidado com a capacitação e sensibilização do grupo de profissionais em relação aos aspectos atitudinais na interação com seus usuários no cotidiano. São incluídos textos que tratam dos princípios que nortearam o trabalho, especialmente o conceito de acessibilidade e o de desenho universal, que, para além dos aspectos 
formais, incluem a preocupação com a apropriação de sentido pelos seus usuários. Os capítulos abordam vários aspectos da legislação às tecnologias assistivas, os cuidados necessários para garantir acessibilidade na web e os serviços e produtos de uma biblioteca acessível.

No que se refere à acessibilidade na WEB, a equipe salienta para a necessidade de atender as normas do Decreto $n^{\circ} 5.296$ de 2 de Dezembro de 2004 e suas orientações (W3C Brasil) na construção de páginas e portais na Internet, e, principalmente, na escolha do formato da publicação de conteúdos para viabilizar que qualquer pessoa possa navegar na web, independente da tecnologia utilizada, para interagir e obter informações nos diversos provedores de informação e diferente configurações de acesso.

Outras experiências bem-sucedidas, no que tange à disponibilização de tecnologias assistivas para atendimento a usuários com diferentes deficiências, começam a ser observadas em várias bibliotecas públicas e universitárias do país.

0 investimento de empresas no desenvolvimento de equipamentos de auxílio à mobilidade e softwares para auxílio às $\mathrm{PcD}$ visual ou aditiva como vídeos ampliadores de texto e imagem, lupas eletrônicas e máquinas para produção de textos em Braille, para gravação de áudios e narração em dispositivos portáteis, abrem opções de escolha e aquisição para bibliotecas brasileiras, mas a carência de recursos financeiros ainda é impeditivo para garantir o direito ao acesso à informação por grande parte das PcD.

Também é importante observar que, apesar da disponibilização de tecnologias assistivas ser essencial para garantir o acesso à informação por PcD, é necessário que os espaços culturais e de informação mantenham equipes capacitadas em comunicação inclusiva para acolher tais usuários e oferecer apoio e orientação no uso dessas tecnologias.

Em relação aos aspectos cognitivos, o quadro se apresenta ainda mais carente de intervenções públicas, no que se refere aos serviços de referência em dispositivos de informação e cultura, pois, segundo Marta Gil (2005), exige a formação de equipe com competência em comunicação simplificada para atendimento a pessoas com deficiência intelectual, pessoas com baixo letramento e surdos que usam Libras - língua brasileira de sinais, mas têm dificuldade de compreender textos em português, como sua $2 \mathrm{a}$. língua. 
Por outro lado, a construção de diálogos inclusivos e significativos entre profissionais de informação e usuários depende fundamentalmente da capacidade de as equipes compreenderem as demandas do público no contexto de uso das informações, para viabilizar serviços de referência customizados de acordo com necessidades e comportamento informacional dos potenciais usuários, o que depende não apenas da oferta por parte dos provedores, mas do conhecimento sobre as possibilidades de apropriação dos consumidores e, no que se refere à acessibilidade informacional, às interfaces disponíveis para mediar processos de exploração das fontes e respectivos usuários.

\section{CIÊNCIA DA INFORMAÇÃO E SUA CONTRIBUIÇÃO PARA A INSERÇÃO SOCIAL DA INFORMAÇÃO E INCLUSÃO SOCIAL}

Partindo do pressuposto que a Informação é recurso fundamental para a construção de novos conhecimentos e constituição de novos domínios científicos, como proposto por Tálamo e Smit (2019), e retomando reflexões propostas por Frohman (2008) que defende que os processos informacionais só podem ser compreendidos no interior de regimes de informação, os quais materializam dispositivos regrados social e politicamente, a questão que colocamos é : no caso brasileiro, as políticas públicas de informação, vistas na perspectiva da Ciência da Informação, embutem preocupação com o usuário? Atuam no sentido de criar práticas sociais e informacionais de interação significativa com os cidadãos? Ou apenas refletem a imposição da lei, mas sem a preocupação com os princípios de inclusão social?

Bordieu (1989) ao tratar dos problemas de legitimação do conhecimento científico na sociedade e das disputas de poder entre os que o exercem e os que são sujeitos da ação, trata da existência do poder simbólico como " o poder de constituir o dado pela enunciação, de fazer ver e fazer crer, de confirmar ou de transformar a visão de mundo, e deste modo, a ação sobre o mundo" (BORDIEU, 1989. p. 14) Neste sentido, é importante que políticas de Estado sejam analisadas criticamente para evitar que sejam utilizadas para legitimar sistema de dominação vigente, mas que mascaram a realidade social. 
A legislação brasileira estabelece princípios, responsabilidades e obrigações das várias instâncias para assegurar o acesso à informação por parte dos cidadãos, mas é responsabilidade dos pesquisadores da Ciência da Informação estudar e investigar carências e dificuldades a serem sanadas na implementação da legislação visando promover qualificação da ação informacional e garantir melhores condições de acessibilidade do ponto de vista físico e também cognitivo.

Conforme Le Coadic (2001, p.516), cabe à Ciência da Informação "estudar as propriedades gerais da informação e analisar os processos que envolvem sua produção, comunicação e uso, processos hoje fortemente associados às tecnologias de informática".

Neste sentido, Tálamo e Smit (2007, p.20-21), em discussão sobre os aspectos constitutivos da Ciência da Informação, observam que o ato de conhecer é vinculado a aspectos de cognição e associado à ação humana, de modo que o conhecimento seria o próprio modo de inserção no mundo. Apontam, entretanto, que o conhecimento na atualidade se encontra despersonalizado e fragmentado e propõem um programa de trabalho, no domínio da Ciência da Informação, que contemple elementos que propiciem simultaneamente aspectos da inserção social da informação, estudo da atividade dos usuários-consumidores e a análise das condições locais de recepção. São eles:

\begin{abstract}
A articulação entre os dispositivos tecnológicos da informação e a produção da informação e a geração de sentido; A inserção social da informação, com determinação de condições locais de recepção, visando o aperfeiçoamento dos dispositivos. Estudo da atividade dos usuários-consumidores; Identificação dos códigos explicitadores do conhecimento sob a forma de informação e das condições que presidem sua concepção e realização; Dimensão sociológica, política e econômica das atividades informacionais; Estudo das mudanças ocorridas nos processos de mediação. (TALAMO; SMIT,2007. p. 52).
\end{abstract}

De fato, é essencial observar a articulação entre os dispositivos de informação, a produção da informação e a geração de sentido, bem como as condições locais de recepção, visando o aperfeiçoamento dos dispositivos, pois, como salienta Sofia Pérez Ferrés em discussão sobre acessibilidade física

É importante constatar que é o ambiente que gera exclusão e, de fato, é o que gera deficiência. Um ambiente preparado para as diferenças não exclui e permite o acesso e a integração plena, desde o ponto de vista funcional e psicológico, naquelas atividades diárias realizadas por todos, redefinindo assim o próprio conceito de deficiência (PUPO; MELO; FERRÉS, 2008 p.22). 
De igual maneira, estudos da atividade dos usuários-consumidores e estudos que visem a identificação dos códigos explicitadores do conhecimento sob a forma de informação e das condições que presidem sua concepção e realização, conforme proposto por Tálamo e Smit (2007), acima citado, são fundamentais para garantir que todas as pessoas tenham direito ao acesso à informação, pois como preconizado na cartilha da Secretaria de Direitos Humanos da Presidência da República

\begin{abstract}
Pessoas com deficiência são, antes de mais nada, PESSOAS. Pessoas como quaisquer outras, com protagonismos, peculiaridades, contradições e singularidades. Pessoas que lutam por seus direitos, que valorizam o respeito pela dignidade, pela autonomia individual, pela plena e efetiva participação e inclusão na sociedade e pela igualdade de oportunidades, evidenciando, portanto, que a deficiência é apenas mais uma característica da condição humana. (SECRETARIA, 2010)
\end{abstract}

Assim, embora o país tenha avançado consideravelmente em relação à legislação que assegura direitos de acesso à informação ao cidadão e em legislações específicas que garantem condições de acessibilidade à informação pública por $\mathrm{PcD}, \mathrm{a}$ discussão sobre acessibilidade informacional ainda carece de estudos sobre os potenciais consumidores e, principalmente, sobre necessidades de informação e condições de recepção, para viabilizar estratégias mais eficientes de acesso à informação que considerem especificidades e práticas de diferentes grupos de usuários.

São desafios consideráveis do ponto de vista teórico-metodológico para realização de estudos que possam subsidiar não apenas a concepção, mas, sobretudo, mecanismos efetivos de implementação de políticas públicas de acesso à informação para todos os cidadãos.

A formação de cidadãos a partir de uma visão de educação inclusiva é responsabilidade de todos, e como diz Marta Gil (2005)

Educação Inclusiva não é uma moda passageira. Ela é o resultado de muitas discussões, estudos teóricos e práticas que tiveram a participação e o apoio de organizações de pessoas com deficiência e educadores, no Brasil e no mundo. Fruto também de um contexto histórico em que se resgata a Educação como lugar do exercício da cidadania e da garantia de direitos. (GIL, 2005, p.16). 


\section{REFERÊNCIAS}

AMANKAY INSTITUTO DE ESTUDOS E PESQUISA. Educação inclusiva. Disponível em: <http://www.amankay.org.br/educacao_inclusiva/educacao_inclusiva.php> Acesso em: 05 jun. 2017.

ASSOCIAÇÃO BRASILEIRA DE NORMAS TÉCNICAS (ABNT). ABNT-NBR 9050 (2004): Acessibilidade a edificações, mobiliário, espaços e equipamentos urbanos. Rio de Janeiro: 2004. Disponível em:

<http://www.pessoacomdeficiencia.gov.br/app/sites/default/files/arquivos/\%5Bfield_ generico_imagens-filefield-description\%5D_24.pdf> Acesso em: 07 mai. 2017.

BOURDIEU, P. A Escola conservadora: as desigualdades frente à escola e à cultura. In: NOGUEIRA, M. A.; CATANI. Afrânio (Orgs). Escritos de educação. Petrópolis, Vozes, 1998.

BOURDIEU, Pierre. 0 poder simbólico. Tradução de Fernando Tomaz. Rio de Janeiro: Bertrand Brasil, 1989.

BOURDIEU, M. Os Usos Sociais da Ciência: por uma sociologia clínica do campo científico. São Paulo: Unesp, 2004.

BRASIL. Constituição da República Federativa do Brasil de 1988. 5 de outubro de 1988. Disponível em:

<http://www.planalto.gov.br/ccivil_03/Constituicao/Constituicao.htm> Acesso em: 07 mar. 2017

. Constituição da República Federativa do Brasil: promulgada em 5 de outubro de 1988. Organização do texto: Juarez de Oliveira. 4. ed. São Paulo: Saraiva, 1990.

Decreto № 3.956, de 8 de Outubro de 2001. Promulga a Convenção Interamericana para a Eliminação de todas as Formas de Discriminação contra as Pessoas Portadoras de Deficiência. Diário Oficial [da] República Federativa do Brasil, Brasília, DF, 9 out. 2001.

Decreto no 5.296 de 2 de dezembro de 2004. Regulamenta as Leis no 10.048 , de 8 de novembro de 2000 , que dá prioridade de atendimento às pessoas que especifica, e 10.098, de 19 de dezembro de 2000, que estabelece normas gerais e critérios básicos para a promoção da acessibilidade das pessoas portadoras de deficiência ou com mobilidade reduzida, e dá outras providências. In: Diário Oficial da União, Brasília, 2004.

. Lei no 10.436 de 24 de abril de 2002. Dispõe sobre a Língua Brasileira de Sinais - Libras e dá outras providências. In: Diário Oficial da União, Brasília, 2002.

Lei no 12.527, de 18 de novembro de 2011. Regula o acesso a informações previsto no inciso XXXIII do art. $5^{\circ}$, no inciso II do $\S 3^{\circ}$ do art. 37 e no $\S 2^{\circ}$ do art. 216 da Constituição Federal; altera a Lei $n^{\circ}$ 8.112, de 11 de dezembro de 1990; revoga a Lei $\mathrm{n}^{0} 11.111$, de 5 de maio de 2005, e dispositivos da Lei n 8.159 , de 8 de janeiro de 1991; e dá outras providências. Disponível em: 
<http://www.planalto.gov.br/ccivil_03/_ato2011-2014/2011/lei/l12527.htm> Acesso em: 07mar. 2017

Medida Provisória no 726, de 12 de maio de 2016. Altera e revoga dispositivos da Lei no 10.683, de 28 de maio de 2003, que dispõe sobre a organização da Presidência da República e dos Ministérios. Disponível em:

<http://www.planalto.gov.br/ccivil_03/_Ato2015-2018/2016/Mpv/mpv726.htm>. Acesso em: 07 mar. 2017

CONTROLADORIA-GERAL DA UNIÃO. Acesso à informação pública: uma introdução à lei 12.527, de 18 de novembro de 2011. Brasília, DF: CGU, 2011. 24p.

Manual da Lei de Acesso à Informação para Estados e Municípios. 1 ed. Brasília, DF: CGU, 2013. Disponível em: $<$ http://www.cgu.gov.br/Publicacoes/transparencia-publica/brasiltransparente/arquivos/manual_lai_estadosmunicipios.pdf>. Acesso em: 07 mar. 2017

FROHMANN, Bernd. O caráter social, material e público da informação. In: FUJITA, M.; MARTELETO, R.; LARA, M. (Orgs). A dimensão epistemológica da ciência da informação e suas interfaces técnicas, políticas e institucionais nos processos de produção, acesso e disseminação da informação. São Paulo: Cultura Acadêmica; Marília: Fundepe, 2008, p. 19-34

GIDDENS, A. As consequências da modernidade. Tradução de Raul Filker. São Paulo: UNESP, 1991.

GIL, Marta (Coord.). Educação Inclusiva: o que o professor tem a ver com isso? São Paulo: Imprensa Oficial do Estado de São Paulo, 2005.

IFLA. Código de ética da IFLA para bibliotecários e outros profissionais da informação. Conselho Diretivo da IFLA, agosto 2012 . Disponível em: <https://www.ifla.org/files/assets/faife/codesofethics/portuguesecodeofethicsfull.pdf $>$ Acesso em 26 mai. 2017.

LE COADIC, Yves-François. A ciência da informação. 2 ed. Brasília: Briquet de Lemos, 2004.

PAIM, I.; NEHMY, R. M. Q. Questões sobre a avaliação da informação: uma abordagem inspirada em giddens. Perspectivas em Ciência da Informação, v. 3, n. 2, p. 81-95, 1998.

PUPO, Deise Tallarico; MELO, Amanda Meincke; FERRÉS, Sofia Pérez (Orgs.) Acessibilidade: discurso e prática no cotidiano das bibliotecas. Campinas: Universidade Estadual de Campinas - Biblioteca Central Cesar Lattes - Laboratório de acessibilidade, 2008. 137 páginas. 
RESENDE, Ana Paula Crosara; VITAL, Flavia Maria de Paiva (Coord.). A Convenção sobre os direitos das pessoas com deficiência comentada. Brasília: Secretaria Especial dos Direitos Humanos, 2008.

SÃO PAULO. Lei complementar № 1.038, de 06 de março de 2008. Cria a Secretaria de Estado dos Direitos da Pessoa com Deficiência, e dá providências correlatas. São Paulo, 2008. Disponível em: http://www.pessoacomdeficiencia.sp.gov.br/legislacao. Acesso em: 24 mai. 2017.

SASSAKI, Romeu Kazumi. Conceito de acessibilidade. 2011. Website Escola de Gente. Disponível em: <http://www.escoladegente.org.br/noticiaDestaque.php?id=459>. Acesso em: 07 mar. 2017

SECRETARIA de Direitos Humanos da Presidência da República. Cartilha do Censo 2010: Pessoa com deficiência. Brasília: Secretaria Nacional de Promoção dos Direitos da Pessoa com Deficiência, 2012. Disponível em: <

http://www.pessoacomdeficiencia.gov.br/app/sites/default/files/publicacoes/cartilhacenso-2010-pessoas-com-deficienciareduzido.pdf> Acesso em: 04 jun. 2017

SISTEMA NACIONAL DE BIBLIOTECAS PÚBLICAS (SNBP). Projeto Acessibilidade em Bibliotecas Públicas. Disponível em:

$<$ http://acessibilidadeembibliotecas.culturadigital.br/sobre-o-projeto/> Acesso em 28 mai. 2017.

TÁLAMO, Maria.F.G.M.; SMIT, J. W. Information Science: informational concept and disciplinary integration. Brazilian Journal of Information Science, v. 1, n. 1, 2007.

UFC. Acessibilidade. Disponível em: < http://www.ufc.br/acessibilidade/conceito-deacessibilidade > Acesso em 23 mai. 2017

UHLIR, P. F. Diretrizes políticas para o desenvolvimento e a promoção da informação governamental de domínio público. Brasília, DF: Unesco, 2006.

UNESCO. Declaração de Salamanca. Sobre Princípios, Políticas e Práticas na Área das Necessidades Educativas Especiais. Disponível em:

<http://portal.mec.gov.br/seesp/arquivos/pdf/salamanca.pdf> Acesso em: 07 mai. 2017.

UNICAMP. Biblioteca Central. Laboratório de Acessibilidade. Disponível em: < http://www.todosnos.unicamp.br:8080/lab/>. Acesso em 04 mai. 2017

W3C BRASIL. Cartilha Acessibilidade na Web. Disponível em:

<http://www.w3c.br/pub/Materiais/PublicacoesW3C/cartilha-w3cbr-acessibilidadeweb-fasciculo-I.html> Acesso em: 07 mai. 2017. 


\section{SOBRE A AUTORA}

\section{ASA FUJINO}

Professora no Programa de Pós-Graduação em Ciência da informação, da ECA-USP.

Doutora em Ciências da Comunicação pela Escola de Comunicações e Artes da USP.

Mestre em Ciências da Comunicação pela Escola de Comunicações e Artes da USP.

E-mail: asfujino@usp.br.

Recebido em: 25/03/2017; Revisado em: 23/04/2017; Aceito em: 27/05/2017.

\section{Como citar este artigo}

FUJINO, Asa. Acessibilidade Informacional de PcD No Contexto da Lei de Acesso à Informação: desafios para estudo de usuários. Informação em Pauta, Fortaleza, v. 2, número especial, p. 237- 257, out. 2017. 